\title{
Women seek more variety in rewards when closer to ovulation $\downarrow$ ?
}

\author{
Ali Faraji-Rad ${ }^{\text {a,*}}$, Mehrad Moeini-Jazani ${ }^{\text {b }}$, Luk Warlop ${ }^{\text {b,c }}$ \\ ${ }^{a}$ Graduate School of Business, Columbia University, USA \\ ${ }^{\mathrm{b}}$ BI Norwegian Business School, Norway \\ ${ }^{\mathrm{c}}$ KU Leuven, Belgium
}

Received 26 September 2012; received in revised form 4 May 2013; accepted 10 May 2013

\begin{abstract}
We propose that women's increased generalized sensitivity to rewards during the fertile phase of the menstrual cycle causes them to seek more variety in rewards when they are in the fertile phase than when they are not in the fertile phase of the cycle. In Studies $1-3$, across the reward domains of mating and hedonic food, we show that women seek more variety in rewards when closer to ovulation. Moreover, we provide support for the proposition that women's increased reward sensitivity during the fertile phase of the menstrual cycle causes their greater variety seeking. Specifically, in Study 3, we show that fertile women's greater variety seeking does not extend to non-rewards, such as non-hedonic food. Our findings suggest that behavioral effects of women's hormonal shifts during the menstrual cycle are not limited to the mating domain and may extend to a wide category of reward domains.
\end{abstract}

(C) 2013 Society for Consumer Psychology. Published by Elsevier Inc. All rights reserved.

Keywords: Fertility; Reward sensitivity; Variety seeking

\section{Introduction}

The effects of hormonal fluctuations during the ovulatory cycle on women's behavior have been subject to considerable research. For example, when in the menstrual cycle's fertile phase, women prefer partners who are more masculine (Gangestad, Garver-Apgar, Simpson, \& Cousins, 2007; Penton-Voak et al., 1999), have deeper male voices (Puts, 2005), and display greater social presence and dominance (Gangestad, Simpson, Cousins, Garver-Apgar, \& Christensen, 2004). Fertile women are faster in categorizing masculine men (Macrae, Alnwick, Milne, \& Schloerscheidt, 2002) and are more accurate in predicting men's sexual orientation (Rule, Rosen, Slepian, \& Ambady, 2011). Women also prefer to wear more revealing clothing (Durante, Li,

\footnotetext{
The research fund at the Department of Marketing, BI Norwegian Business School funded this research. Authors thank Michel Tuan Pham for his helpful comments.

* Corresponding author at: Graduate School of Business, Columbia University, 3022 Broadway, Uris 5C, New York, NY 10027-6902, USA.

E-mail address: af2560@columbia.edu (A. Faraji-Rad).
}

\& Haselton, 2008) and show more attention to luxury products (Lens, Driesmans, Pandelaere, \& Janssens, 2012) when closer to ovulation.

The effects of fertility on women's behavior, such as those reviewed above, have primarily been explained in accordance with women's increased mating motivations during the fertile period of the ovulatory cycle, and the evolutionary advantages of such behaviors. However, can hormonal fluctuations during the ovulatory cycle lead to behaviors not directly related to women's mating motives? In this research, building on previous evidence for fertile women's increased sensitivity to rewards (Dreher et al., 2007; Frank, Kim, Krzemien, \& van Vugt, 2010; Terner \& de Wit, 2006) we propose that the answer to this question is yes. Specifically, we propose that women seek more variety in rewards (vs. non-rewards), when in the fertile (vs. nonfertile) phase of the ovulatory cycle. By variety seeking we mean the tendency to choose a greater variety of rewards, while keeping the total amount of rewards constant (Goukens, Dewitte, Pandelaere, \& Warlop, 2007; Levav \& Zhu, 2009). Thus, variety seeking is not associated with wanting more rewards, but rather with wanting different kinds of the same reward. 


\section{Reward sensitivity, ovulation, and variety seeking}

One way our brain regulates and controls behavior is by producing a positive hedonic sensation (i.e., pleasure) in response to rewarding stimuli or outcomes. Research shows that a distinct dopaminergic neural circuit in the brain responds to rewarding stimuli, and processes rewards (Berridge \& Kringelbach, 2008). Importantly, the brain's neural reward system is domainindependent. That is, the same dopaminergic reward circuitry processes a wide variety of rewards across different reward categories (Camerer, Loewenstein, \& Prelec, 2005). For example, the same reward circuitry responds to rewarding food, psychoactive drugs, monetary rewards, beautiful faces, and erotic stimuli (Aharon et al., 2001; Stark et al., 2005; Wilson \& Daly, 2004). The generalized nature of the brain's reward circuitry leads to reward-related behavioral outcomes that are domainindependent. For example, Van den Bergh, Dewitte, and Warlop (2008) observed that when men are exposed to rewarding stimuli in one particular reward domain (e.g., sexy cues), they show impatience in other reward domains (e.g., monetary rewards). Multiple sources of evidence suggest that women are more sensitive to rewarding stimuli when closer to ovulation. First, neuroimaging evidence demonstrates that women closer to ovulation show higher reward-related neural activity when facing rewarding stimuli such as monetary rewards (Dreher et al., 2007) and rewarding food (Frank et al., 2010). Second, research on drug abuse shows that women's subjective and behavioral responses to amphetamine and cocaine (commonly known rewarding stimuli) are greater when they are closer to ovulation (Terner \& de Wit, 2006). Because of the generalized nature of the brain's reward processing system, women's heightened sensitivity to rewards during fertility may affect their behavior similarly across different reward categories.

How would women's generalized reward sensitivity during fertility cause more variety seeking in rewards? We believe increased reward sensitivity may, in two ways, induce women to seek more variety. First, research shows that when a desire is activated (e.g., hunger), more items from a choice set (e.g., different kinds of sandwiches) become attractive, and therefore people tend to choose a greater variety of items (Goukens et al., 2007). Increased generalized sensitivity to rewards during fertility may increase the attractiveness of a higher number of reward items in a choice set. The increased attractiveness of a higher number of items may lead women to choose a more widely varied set of items. Second, research shows that people seek more variety in their choices to reduce uncertainty and to minimize the risk of not being satisfied (Kahn \& Lehmann, 1991; Simonson, 1990). Increased reward sensitivity during fertility may generate increased motivation to ensure reward delivery. Women may then attempt to reduce the risk of not receiving a minimal amount of reward by picking a greater variety of items in the set.

Given the above arguments, we predict that fertile (vs. nonfertile) women will seek more variety in rewards. However, we do not predict that fertile (vs. non-fertile) women will seek more variety in non-rewards. Moreover, because using contraceptive pills suppresses the natural flow of hormones during the ovulatory cycle, we do not predict that fertility will affect variety seeking among women using contraceptive pills. We present three studies designed to test our hypotheses. In the domains of mating (Study 1) and hedonic food (Studies 2 and 3), we show that fertile women seek more variety in rewards. Moreover, in the food domain, we show that fertile women seek more variety in hedonic food but not in non-hedonic food (Study 3).

\section{Study 1}

In Study 1, we test the proposition that non-pill using women seek greater variety in dating partners when in the fertile phase of the ovulatory cycle than when not in the fertile phase.

\section{Participants and method}

Through Amazon's Mechanical Turk, we recruited 300 US-resident women, as participants in Study $1\left(M_{\text {Age }}=27.4\right.$, Range $_{\text {Age }}=18-43$ ).

We first showed an array of nine male faces to participants and asked them to imagine they could go on exactly seven consecutive dates, one daily, with any combination of the men. We asked participants to report the number of days they would like to go out with each man. The number of days reported had to total exactly seven. We measured variety seeking by counting the number of men each participant wanted to go out with at least once. Then, participants reported the exact date when their last menstruation started (for currently menstruating participants, this date was the start date of their current menstruation). The reported date would be day one of participants' menstrual cycle. Using this information, we divided participants into fertile (cycle days 9-15) and non-fertile groups (cycle days 1-5 and 18-28) (Miller, Tybur, \& Jordan, 2007). Participants also reported their sexual orientation and whether they used contraceptive pills.

\section{Results}

\section{Preliminary analysis}

Data from 120 participants who reported being homosexual $(n=13)$, did not enter a date on the menstrual cycle question ( $n=18$, because of no menstruation, medical conditions, etc.), fell between the two phases $(n=42)$, or indicated their last menstruation started at least 29 days before the experiment $(n=47)$ were removed from analysis. ${ }^{1}$ Thus, the remaining analysis was conducted on 53 fertile (17 pill users and 36 non-pill users) and 127 non-fertile participants (35 pill users and 92 non-pill users).

\footnotetext{
${ }^{1}$ MTurk participants are more diverse, and on average, older than participants in typical student samples (Buhrmester, Kwang, \& Gosling, 2011), and are more likely to have no or irregular menstruation (because of pregnancy, breastfeeding, menopause, medical condition, etc.). Thus, the rate of removal of participants in our studies is higher than that in studies with typical student samples, but is comparable with that in studies with MTurk samples (Durante et al., 2011, 2012).
} 
Variety seeking behavior

An ANOVA with pill use and fertility as independent factors, and variety seeking as dependent variable, resulted in a significant fertility-by-pill-use interaction $(F(1,176)=5.762$, $p=0.017, \eta^{2}=.032$ ) but no other significant effects (all $p$-values $>.23)$. Follow-up planned contrasts showed that nonpill users pursued more variety when fertile $(M=4.14, S D=$ 1.74) than when not fertile $(M=3.05, S D=1.68, F(1,176)=$ $\left.10.499, p=.001, \eta^{2}=.056\right)$, but this was not true for pill users $\left(M_{\text {Fertile }}=3.18, S D_{\text {Fertile }}=1.84\right.$ vs. $M_{\text {Non-fertile }}=3.54$, $\left.S D_{\text {Non-fertile }}=1.63, F<1\right)$.

\section{Discussion}

In the reward domain of mating, Study 1 shows that fertile women seek greater variety than non-fertile women. Given prior evidence for fertile women's increased preference for masculine partners, could Study 1's findings have been obtained because some of the faces in our stimuli were overly masculine? If so, the men with masculine faces would be seen as unlikely partners by non-fertile women, but not by fertile women. This would render fertile women's consideration set larger than non-fertile women's set-leading to greater variety seeking by fertile women. However, a priori one might as well present the opposite argument, that fertile women's bias toward more masculine men reduces the size of the consideration set by removing the non-masculine men from the set, thus decreasing variety seeking. We had not selected the study's stimuli based on masculinity. However, post hoc analysis (details available from the authors) showed that fertile women chose all of the men in our stimulus set more often than non-fertile women did. This result reduces the likelihood that the study's finding is driven by a few men in the set. We also subsequently asked 40 women from the same population to rate the masculinity of men pictured in our stimuli. In Study 1's data, both the man rated least masculine and the man rated most masculine were selected more often, and at the exact same rate, by fertile women than by non-fertile women. Moreover, a masculinity explanation does not explain the effect of fertility on variety seeking in the domain of hedonic food (Studies 2 and 3). Thus, we consider a masculinity-based alternative explanation for Study 1's findings to be less plausible than the reward sensitivity one, which seems the more parsimonious explanation across all studies.

We have argued that fertile women's increased generalized sensitivity to rewards leads to their greater variety seeking across different reward categories. Does the effect found in Study 1 generalize to other reward domains? Study 2 addresses this question.

\section{Study 2}

In Study 2, we test the proposition that non-pill using women seek greater variety in hedonic food when in the fertile phase of the ovulatory cycle than when not in the fertile phase.

\section{Participants and method}

Through Amazon's Mechanical Turk, we recruited 510 US-resident women as participants in Study $2\left(M_{\text {Age }}=34.2\right.$, Range $\left._{\text {Age }}=18-79\right)$. We first asked participants to imagine they were buying exactly four scoops of ice cream for immediate, personal use and that available flavors were vanilla, coffee, chocolate, and strawberry. Participants indicated any combination of flavors they would order, as long as the scoops totaled four. Then, we asked participants to report their menstruation and pill use information, and assigned them to the fertile and non-fertile groups in a manner similar to Study 1 's.

\section{Results}

\section{Preliminary analysis}

Data from 264 participants were removed because they did not enter a date on the menstrual cycle question $(n=130)$, fell between the two phases $(n=62)$, or indicated their last menstruation started at least 29 days before the experiment $(n=72)$. Thus, we were left with 80 fertile participants ( 25 pill users and 55 non-pill users) and 166 non-fertile participants (53 pill users and 113 non-pill users).

\section{Variety seeking behavior}

An ANOVA similar to Study 1's resulted in a fertility-bypill-use interaction $\left(F(1,242)=3.897, p=0.05, \eta^{2}=.016\right)$, but no other significant effects (all $p$-values $>.27$ ). Follow-up contrasts showed non-pill users pursued more variety when fertile $(M=2.73, S D=.75)$ than when not fertile $(M=2.36$, $\left.S D=0.824, F(1,242)=7.539, p=0.006, \eta^{2}=.03\right)$, but this was not true for pill users $\left(M_{\text {Fertile }}=2.52, S D_{\text {Fertile }}=0.714\right.$ vs. $\left.M_{\text {Non-fertile }}=2.62, S D_{\text {Non-fertile }}=0.86, F<1\right)$.

\section{Discussion}

Study 2 shows that fertile (vs. non-fertile) women seek greater variety in ice cream - a hedonic consumable with no apparent relation to the transfer of genes. This study thus provides support for the argument that the effect of fertility on variety seeking extends to reward domains other than mating. However, is fertile women's greater variety seeking limited to rewards? Studies 1 and 2 could not address this question because they did not include a non-reward condition. Study 3 addresses this question, while replicating the effect found in Study 2.

\section{Study 3}

We have argued that women seek more variety in rewards during the menstrual cycle's fertile phase because they are more reward sensitive during this phase. If our argument is true, fertile (vs. non-fertile) women should seek greater variety in rewarding items, and not in comparable non-rewarding items. In Study 3, we test the prediction that fertile (vs. non-fertile) women not using contraceptive pills seek more variety in hedonic food (i.e., chocolate desserts), but not in non-hedonic food (i.e., vegetable salads). 
A methodological limitation of Studies 1 and 2 was that we assessed participants' fertility by using a forward counting method. Forward counting methods have been widely used in prior research (e.g., Gangestad \& Thornhill, 1998; Gangestad et al., 2004; Lens et al., 2012). However, the method used potentially increases the error in assessing participants' fertility because it assumes that all participants have a 28-day menstrual cycle. To address this limitation, in Study 3, we will assess participants' fertility using a reverse-cycle-day method, which accounts for variation in cycle length among different participants (Durante, Griskevicius, Hill, Perilloux, \& Li, 2011; Durante, Griskevicius, Simpson, Cantu, \& Li, 2012; Saad \& Stenstrom, 2012).

\section{Participants and method}

Through Amazon's Mechanical Turk, we recruited 997 US-resident women as participants in Study $3\left(M_{\text {Age }}=28.1\right.$, Range $\left._{\text {Age }}=18-45\right)$. Participants were randomly assigned to either a hedonic food condition or a non-hedonic food condition. First, we asked participants to imagine that a startup online company, specialized in delivering fresh food to its customers, had provided them with four free promotional vouchers. We showed participants pictures of four food items supposedly from the items available on the website and asked them to indicate how many of each item they would buy with their vouchers. They could buy any combination of items shown as long as the items bought totaled four. Participants in the hedonic-food condition saw pictures of four chocolate desserts, whereas those in the non-hedonic food condition saw pictures of four vegetable salads. We measured variety seeking by counting the food items each participant chose at least once. In a pretest, we showed either the four rewarding or the four non-rewarding items to 52 females from the same population and asked them to indicate how pleasurable consuming each item would be $(1=$ "not pleasurable," 7 = "very pleasurable"). The pretest participants indicated that, on average, consuming the rewarding items $(M=5.72$, $S D=.98$ ) would be more pleasurable than consuming the non-rewarding items $(M=4.58, S D=1.35, F(1,50)=12.205$, $\left.p=.001, \eta^{2}=.196\right)$. After indicating their choices, participants in Study 3 reported the typical length of their menstrual cycle, and reported the start date of their previous, last, and next (predicted) menstrual period. Using these information, we assigned women to fertile (days $8-15$ in a 28 -day cycle) versus non-fertile (days $1-5$ and $18-28$ in a 28 -day cycle) groups based on the reverse-cycle-day method (Durante et al., 2011, 2012).

\section{Results}

\section{Preliminary analysis}

We removed 477 participants who reported no menstruation, irregular menstruation, or a cycle longer than 40 days, or whose cycle days did not fall on the cycle days of interest. Thus, the remaining analysis was conducted on 214 fertile (54 pill users and 160 non-pill users) and 306 non-fertile (94 pill users and 212 non-pill users) participants.

\section{Variety seeking behavior}

An ANOVA with pill use, fertility, and food type as independent variables and variety seeking as dependent variable resulted in a main effect of food type $\left(M_{\text {Rewarding }}=2.88\right.$, $S D_{\text {Rewarding }}=.85$ vs. $M_{\text {Non-rewarding }}=2.27, S D_{\text {Non-rewarding }}=.84$, $\left.F(1,512)=36.5, p<.001, \eta^{2}=.067\right)$ and a significant 3-way interaction $\left(F(1,512)=4.317, p=.038, \eta^{2}=.008\right)$. We did not observe any other interactions or main effects $\left(F_{S}<1\right)$. Among participants who saw the rewarding items, we observed a significant fertility-by-pill-use interaction $(F(1,512)=4.306$, $\left.p=.038, \eta^{2}=.007\right)$, such that fertility did not affect pill users' variety seeking $\left(M_{\text {Fertile }}=2.81, S D_{\text {Fertile }}=.87\right.$ vs. $M_{\text {Non-fertile }}=$ 2.94, $\left.S D_{\text {Non-fertile }}=.84, F(1,512)<1\right)$, but did affect non-pill users' variety seeking $\left(M_{\text {Fertile }}=2.92, S D_{\text {Fertile }}=.82\right.$ vs. $M_{\text {Non-fertile }}=2.62, S D_{\text {Non-fertile }}=.99, F(1,512)=6.463, p=$ $\left..011, \eta^{2}=.010\right)$. However, among participants who saw the non-rewarding items, we did not observe a fertility-by-pill-use interaction $(F(1,512)=1.859, p=.173)$, or any effect of fertility on variety seeking among non-pill users $\left(M_{\text {Fertile }}=\right.$ 2.20, $S D_{\text {Fertile }}=.81$ vs. $M_{\text {Non-fertile }}=2.36, S D_{\text {Non-fertile }}=$ $.86, F<1)$ or pill users $\left(M_{\text {Fertile }}=2.35, S D_{\text {Fertile }}=.86\right.$ vs. $M_{\text {Non-fertile }}=2.18, S D_{\text {Non-fertile }}=.84, F(1,512)=1.937, p=$ $.164)$.

\section{Discussion}

Results of Study 3 support our propositions in two ways. First, the study supports our argument for the relationship between reward sensitivity and variety seeking by showing that women seek more variety when choosing between rewarding items versus non-rewarding items. Second, the study showed that fertile women seek greater variety in rewarding food (replicating Study 2's findings), but not non-rewarding food, thus supporting the argument that fertile women's greater variety seeking is because of their increased sensitivity to rewards.

Results of Studies 2 and 3 must be discussed in relation to prior evidence on the relationship between women's fertility and their food intake. Although the findings have been disputed (Bryant, Truesdale, \& Dye, 2006; Piers et al., 1995; Tomelleri \& Grunewald, 1987), evidence suggests that women's calorie intake is higher during the menstrual cycle's non-fertile period than during the fertile period (Fessler, 2003; Saad \& Stenstrom, 2012). Tentatively, the effect has been attributed to an adaptive decrease in the set point for satiation during fertility, to reduce the salience of goals that compete with women's mating goals (Fessler, 2003). Study 2 and 3's results may, at first sight, seem inconsistent with these data. How can women have an increased desire for rewards (including for food), but consume less food during the menstrual cycle's fertile phase? However, as discussed earlier, we operationalized variety seeking independent of the amount of food consumed. Hence, our data does not address women's amount of food consumption during the ovulatory cycle. It may be that while women have increased sensitivity to rewards during the menstrual cycle's fertile phase, other processes during the same period decrease the set point for satiation, leading to fewer total calories consumed. 


\section{General discussion}

Across reward domains of mating (Study 1) and hedonic food (Studies 2 and 3), for the first time, we showed that women seek more variety in rewards when they are closer to ovulation. Moreover, we showed that women's increased variety seeking during the fertile phase of the ovulatory cycle is not generalized to non-rewards (Study 3). We argued that women's generalized sensitivity to rewards during the fertile phase of the ovulatory cycle contributes to their greater variety seeking in this period. However, how does fertile women's greater reward sensitivity cause a greater variety seeking in rewards? We presented two possible mechanisms. First, increased reward sensitivity may cause an increased liking of a higher number of reward items in the choice set, leading to more widely varied reward items being chosen (increased liking mechanism). Second, increased reward sensitivity may generate an increased motivation to ensure reward delivery, leading women to seek variety to reduce the risk of not receiving a minimal amount of rewards (risk reduction mechanism).

Although in this paper we only speculated about the two possible mechanisms that cause greater variety seeking, we believe future research would benefit from testing them. These two mechanisms may be used to make further predictions about ovulating women's variety seeking. For example, the proposed risk reduction mechanism would predict that riskaverse (vs. non-risk averse) women seek greater variety in rewards when fertile (vs. non-fertile). This is because the risk of not receiving a minimal amount of reward may be more aversive for risk-averse women. On the other hand, the proposed increased liking mechanism would predict that fertile (vs. non-fertile) women's variety seeking is greatest among women who have a higher disposition to enjoy rewards (e.g., women who are more open to experience). While the increased liking and risk reduction mechanisms make different predictions about women's variety seeking, we do not see them as competing processes. In other words, both processes may contribute to higher variety seeking. However, their contributions may differ depending on the situation and personal dispositions.

Most prior research has investigated the behavioral effects of women's ovulatory shifts by focusing on their increased mating motives during the fertile phase of the ovulatory cycle. Such research has mainly relied on domain-specific theories of evolutionary psychology to explain fertility effects (for excellent reviews relating research on evolutionary psychology to consumer behavior, see Saad, 2007, 2011; Saad \& Gill, 2000). Given appropriate assumptions, increased variety seeking in the mating domain (Study 1) by fertile women may be explained with evolutionary psychology accounts. However, variety seeking for hedonic food (Studies 2 and 3) is much harder to relate to those accounts. We therefore do not think that an evolutionary psychology account would explain our findings. Instead, as argued before, research in biology, which has demonstrated women's increased domain-independent sensitivity to rewards during fertility, provides a more suitable theoretical basis for our effects (Dreher et al., 2007; Frank et al., 2010; Terner \& de
Wit, 2006). We believe our findings are interesting because they show that hormonal shifts during the menstrual cycle affect women's behavior in domains unrelated to sex and mating. Prior research may have overlooked the effects of fertility in nonmating domains because of an almost exclusive reliance on evolutionary psychology accounts to explain fertility's effects.

However, we do not consider women's increased sensitivity to rewards during the menstrual cycle's fertile phase to be inconsistent with an evolutionary account. As previously suggested by Dreher et al. (2007), fertile women's increased sensitivity to rewards and the consequent reward oriented behavior may have contributed to facilitation of reproduction. In other words, women's increased reward sensitivity during ovulation may have been caused by sexual selection. However, because of the reward system's generalized nature, which is phylogenetically very old (Berridge \& Kringelbach, 2008), this increased sensitivity to rewards has led to non-mating-specific side effects. ${ }^{2}$ The suggestion made by Dreher et al. (2007) is interesting because it may help identify the more proximate (and biological) causes of some of women's mating-motivated behavior-identified in the literature (e.g., Gangestad et al., 2007; Penton-Voak et al., 1999; Puts, 2005). For example, the proximate cause of fertile women's stronger attraction to masculine traits may be that the reward associated with having partners with masculine traits is of more value for fertile women, who are more reward sensitive (Dreher et al., 2007). If this suggestion is true, further research could investigate how mating-unrelated factors affecting reward sensitivity interact with ovulatory shifts to produce mating-related effects. For example, research has suggested that people are more reward sensitive when in positions of power (Keltner, Gruenfeld, \& Anderson, 2003), or when hungry (Goukens et al., 2007). Thus, future research could investigate how being powerful, or hungry, affects women's preference for masculine partners across the menstrual cycle.

\section{References}

Aharon, I., Etcoff, N., Ariely, D., Chabris, C. F., O'Connor, E., \& Breiter, H. C. (2001). Beautiful faces have variable reward value: fMRI and behavioral evidence. Neuron, 32(3), 537-551.

Berridge, K. C., \& Kringelbach, M. L. (2008). Affective neuroscience of pleasure: Rewards in humans and animals. Psychopharmacology, 199, 457-480.

Bryant, M., Truesdale, K. P., \& Dye, L. (2006). Modest changes in dietary intake across the menstrual cycle: Implications for food intake research. British Journal of Nutrition, 96, 888-894.

Buhrmester, M., Kwang, T., \& Gosling, S. D. (2011). Amazon's mechanical Turk: A new source of inexpensive, yet high-quality, data? Perspectives on Psychological Science, 6, 3-5.

Camerer, C., Loewenstein, G., \& Prelec, D. (2005). Neuroeconomics: How neuroscience can inform economics. Journal of Economic Literature, 43(1), 9-64.

Chiappe, D., \& MacDonald, K. (2005). The evolution of domain-general mechanisms in intelligence and learning. The Journal of General Psychology, $132(1), 5-40$.

\footnotetext{
${ }^{2}$ In line with arguments presented here, some evolutionary theorists agree with the existence of a variety of domain-general mechanisms, in addition to evolved domain-specific motivational dispositions (Chiappe \& MacDonald, 2005; MacDonald, 1991; Saad, 2007).
} 
Dreher, J. C., Schmidt, P. J., Kohn, P., Furman, D., Rubinow, D., \& Berman, K. F. (2007). Menstrual cycle phase modulates reward-related neural function in women. Proceedings of the National Academy of Sciences of the United States of America, 104, 2465-2470.

Durante, K. M., Griskevicius, V., Hill, S. E., Perilloux, C., \& Li, N. P. (2011). Ovulation, female competition, and product choice: Hormonal influences on consumer behavior. Journal of Consumer Research, 37(6), 921-934.

Durante, K. M., Griskevicius, V., Simpson, J. A., Cantu, S. M., \& Li, N. P. (2012). Ovulation leads women to perceive sexy cads as good dads. Journal of Personality and Social Psychology, 103(2), 292-305.

Durante, K. M., Li, N. P., \& Haselton, M. G. (2008). Changes in women's choice of dress across the ovulatory cycle: Naturalistic and laboratory task-based evidence. Personality and Social Psychology Bulletin, 34, 1451-1461

Fessler, D. M. T. (2003). No time to eat: An adaptationist account of ovulatory behavioral changes. The Quarterly Review of Biology, 78, 3-21.

Frank, T. C., Kim, G. L., Krzemien, A., \& van Vugt, D. A. (2010). Effect of menstrual cycle phase on corticolimbic brain activation by visual food cues. Brain Research, 1363, 81-92.

Gangestad, S. W., Garver-Apgar, C. E., Simpson, J. A., \& Cousins, A. J. (2007). Changes in women's mate preferences across the ovulatory cycle. Journal of Personality and Social Psychology, 92(1), 151-163.

Gangestad, S. W., Simpson, J. A., Cousins, A. J., Garver-Apgar, C. E., \& Christensen, P. N. (2004). Women's preferences for male behavioral displays change across the menstrual cycle. Psychological Science, 15, 203-207.

Gangestad, S. W., \& Thornhill, R. (1998). Menstrual cycle variations in women's preferences for scent of symmetrical men. Proceedings of the Royal Society B: Biological Sciences, 265, 927-933.

Goukens, C., Dewitte, S., Pandelaere, M., \& Warlop, L. (2007). Wanting a bit(e) of everything. The role of appetitive desire in variety seeking. Journal of Consumer Research, 34, 386-394.

Kahn, B., \& Lehmann, D. R. (1991). Modeling choice among assortments. Journal of Retailing, 67(Fall), 274-299.

Keltner, D., Gruenfeld, D. H., \& Anderson, C. (2003). Power, approach, and inhibition. Psychological Review, 110(2), 265-284.

Lens, I., Driesmans, K., Pandelaere, M., \& Janssens, K. (2012). Would male conspicuous consumption capture the female eye? Menstrual cycle effects on women's attention to status products. Journal of Experimental Social Psychology, 48, 346-349.

Levav, J., \& Zhu, R. (2009). Seeking freedom through variety. Journal of Consumer Research, 36, 600-610.

MacDonald, K. (1991). A perspective on Darwinian psychology: The importance of domain-general mechanisms, plasticity, and individual differences. Ethology and Sociobiology, 12, 449-480.
Macrae, C. N., Alnwick, K. A., Milne, A. B., \& Schloerscheidt, A. M. (2002). Person perception across the menstrual cycle: Hormonal influences on socialcognitive functioning. Psychological Science, 13(6), 532-536.

Miller, G., Tybur, J. M., \& Jordan, B. D. (2007). Ovulatory cycle effects on tip earnings by lap dancers: Economic evidence for human estrus? Evolution and Human Behavior, 28, 375-381.

Penton-Voak, I. S., Perrett, D. I., Castles, D., Burt, M., Koyabashi, T., \& Murray, L. K. (1999). Female preference for male faces changes cyclically. Nature, 399, 741-742.

Piers, L. S., Diggavi, S. N., Rijskamp, J., Van Raaij, J. M. A., Shetty, P. S., \& Hautvast, J. G. A. J. (1995). Resting metabolic rate and thermic effect of a meal in the follicular and luteal phases of the menstrual cycle in wellnourished Indian women. American Journal of Clinical Nutrition, 61, 296-302.

Puts, D. A. (2005). Menstrual phase and mating context affect women's preferences for male voice pitch. Evolution and Human Behavior, 26, 388-397.

Rule, N. O., Rosen, K. S., Slepian, M. L., \& Ambady, N. (2011). Mating interest improves women's accuracy in judging male sexual orientation. Psychological Science, 22(7), 881-886.

Saad, G. (2007). The evolutionary bases of consumption. New York NY: Psychology Press.

Saad, G. (2011). The consuming instinct: What juicy burgers, Ferraris, pornography, and gift giving reveal about human nature. New York, NY: Prometheus Books.

Saad, G., \& Gill, T. (2000). Applications of evolutionary psychology in marketing. Psychology and Marketing, 17, 1005-1034.

Saad, G., \& Stenstrom, E. (2012). Calories, beauty, and ovulation: The effects of the menstrual cycle on food and appearance-related consumption. Journal of Consumer Psychology, 22, 102-113.

Simonson, I. (1990). The effect of purchase quantity and timing on varietyseeking behavior. Journal of Marketing Research, 27(May), 150-162.

Stark, R., Schienle, A., Girod, C., Walter, B., Kirsch, P., Blecker, C., et al. (2005). Erotic and disgust-inducing pictures: Differences in the hemodynamic responses of the brain. Biological Psychology, 70(1), 19-29.

Terner, J. M., \& de Wit, H. (2006). Menstrual cycle phase and responses to drugs of abuse in humans. Drug and Alcohol Dependence, 84(1), 1-13.

Tomelleri, R., \& Grunewald, K. K. (1987). Menstrual cycle and food cravings in young college women. Journal of the American Dietetic Association, 87, 311-315.

Van den Bergh, B., Dewitte, S., \& Warlop, L. (2008). Bikinis instigate generalized impatience in intertemporal choice. Journal of Consumer Research, 35(1), 85-97.

Wilson, M., \& Daly, M. (2004). Do pretty women inspire men to discount the future? Proceedings of the Royal Society B: Biological Sciences, 271(4), $177-179$. 